\title{
Progress Report on
} Model Development for the Transport of Aerosol through Microchannels

\section{Spent Fuel and Waste Disposition}

\author{
Prepared for \\ US Department of Energy \\ Spent Fuel and Waste Science and \\ Technology \\ Stylianos Chatzidakis \\ Oak Ridge National Laboratory \\ July 30, 2020 \\ M3SF-20OR010207032 \\ ORNL/SPR-2020/1599
}


This report was prepared as an account of work sponsored by an agency of the United States Government. Neither the United States Government nor any agency thereof, nor any of their employees, makes any warranty, express or implied, or assumes any legal liability or responsibility for the accuracy, completeness, or usefulness of any information, apparatus, product, or process disclosed, or represents that its use would not infringe privately owned rights. Reference herein to any specific commercial product, process, or service by trade name, trademark, manufacturer, or otherwise, does not necessarily constitute or imply its endorsement, recommendation, or favoring by the United States Government or any agency thereof. The views and opinions of authors expressed herein do not necessarily state or reflect those of the United States Government or any agency thereof.

This report documents work performed under the Spent Fuel and Waste Disposition Campaign for the US Department of Energy Office of Nuclear Energy. This work was performed to fulfill the Level 3 milestone M3SF-20OR010207031 "Development and validation of phenomenological model on aerosol transport and plugging through stress corrosion cracks" within work package SF $200 R 01020703$ "Stress Corrosion Cracking - ORNL." 


\section{SUMMARY}

Accuracy of consequence assessments could be improved by accounting for the leak path deposition of aerosol in the source term. Recent experimental measurements from Sandia (2018) provided evidence of partial microchannel plugging due to particulate deposition. This filtration effect is relevant to the source term assessments and it is not unreasonable to anticipate that aerosol deposition in more realistic geometries could even lead to complete plugging of the leak path.

This report summarizes current progress (as of end of Q3 FY 2020) on the development of a phenomenological model of aerosol transport, deposition, and plugging through microchannels. The purpose is to introduce a generic, reliable numerical model for the prediction of aerosol transport, deposition, and plugging in leak paths while accounting for potential plugging formation. This report includes (1) an overview of recent additions and improvements on the recently developed numerical model to analyze the various deposition processes in leak paths, to provide quantitative estimates of penetration factors, and to gain an understanding of the variables that affect them and (2) a summary of recent benchmarking results of the model's validity with recent experimental measurements from Sandia.

It is found that aerosol deposition on canister walls would occur from a cloud with homogeneous distribution due to thermal flow convection and is only possible when the particles penetrate into the stagnant boundary layer in contact with the walls. Typically, larger particles $(>1 \mu \mathrm{m})$ are removed by gravitation deposition whereas smaller particles $(<0.1 \mu \mathrm{m})$ deposit due to diffusive deposition. A temperature difference of $0.01^{\circ} \mathrm{C}$ in a canister with an effective wall length of four meters is capable of keeping an aerosol cloud consisting of particles smaller than $20 \mu \mathrm{m}$ homogenously distributed inside the canister. This is a direct consequence of the large difference between convective flow velocity, in the order of $10-20 \mathrm{~cm} / \mathrm{s}$ or higher, and particle's settling velocity which is several orders of magnitude lower $\left(\sim 10^{-3} \mathrm{~cm} / \mathrm{s}\right)$.

Further, it is shown that within enclosure volumes within range of typical canisters, a homogeneously distributed monodisperse aerosol will decay exponentially due to gravitational settling with a decay constant for particles of $1 \mu \mathrm{m}$ aerodynamic diameter is $0.02 \mathrm{hr}^{-1}$ and a half-life of $34.6 \mathrm{hrs}$. For $0.1 \mu \mathrm{m}$ aerodynamic diameter the decay constant is $0.002 \mathrm{hr}^{-1}$ with a half-life of $346 \mathrm{hrs}$. Similarly, for $10 \mu \mathrm{m}$ aerodynamic diameter, the decay constant is $0.2 \mathrm{hr}^{-1}$ with a half-life of $3.46 \mathrm{hrs}$. Coagulation and diffusive deposition are expected to decrease these times even further.

Finally, model comparisons with recent Sandia flow rate measurements showed that flow of gas at the microscale has fundamental differences with respect to flow at the conventional scales. The primary difference appears to be that slipping of gas may occur at solid-gas interface, as opposed to no-slip boundary conditions at the conventional scales. As a result, conventional friction factor correlations may not be directly applicable and laminar to turbulent transitions appear to happen at lower Reynolds number (100-400 instead of 2,300-4,000). 
This page is intentionally left blank. 


\section{ACKNOWLEDGMENTS}

This research was sponsored by the Spent Fuel and Waste Science and Technology Program of the US Department of Energy and was carried out at Oak Ridge National Laboratory under contract DE-AC05-00OR22725 with UT-Battelle, LLC.

This report was developed with significant contributions, expert input, and guidance from Sam Durbin and Eric Lindgren at Sandia National Laboratories and Andy Casella at Pacific Northwest National Laboratory.

The author would like to thank Sylvia Saltzstein at Sandia National Laboratories, Brady Hanson at Pacific Northwest National Laboratory, and Rose Montgomery and Rob Howard at Oak Ridge National Laboratory for providing guidance and support to this project. 
This page is intentionally left blank. 


\section{CONTENTS}

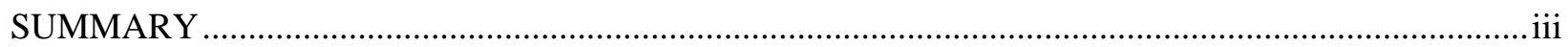

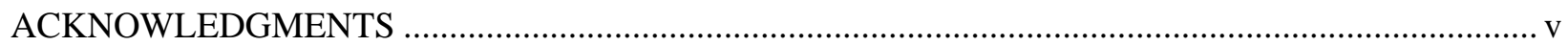

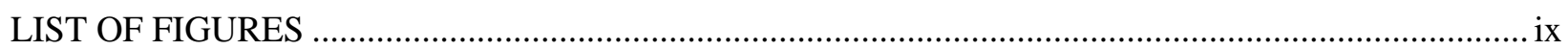

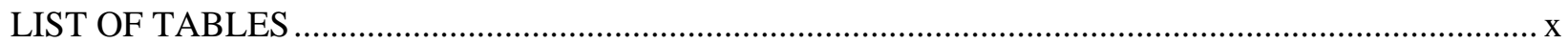

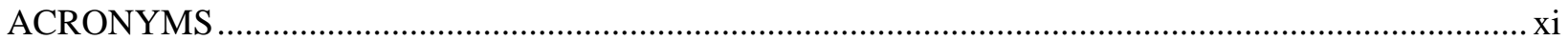

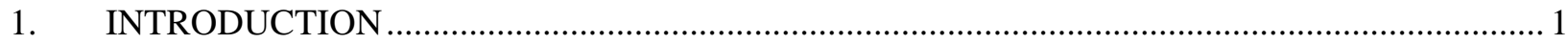

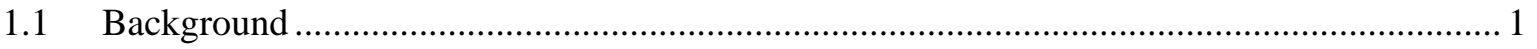

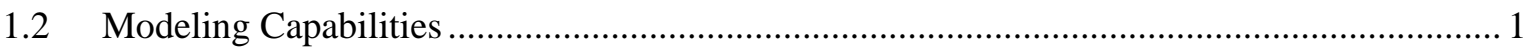

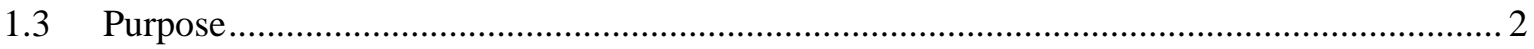

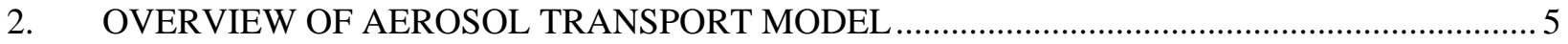

2.1.1 Aerosol Coagulation and Deposition within Canister ............................................ 5

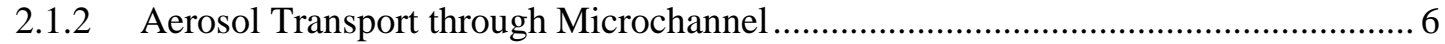

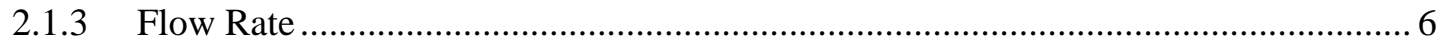

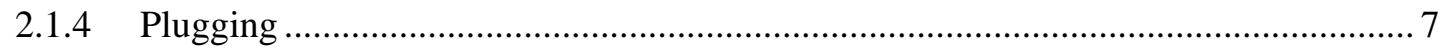

2.1.5 Depressurization and Transient State …............................................................ 7

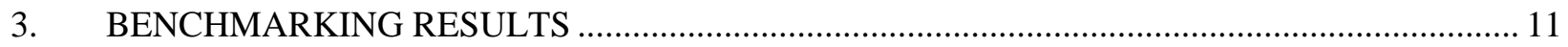

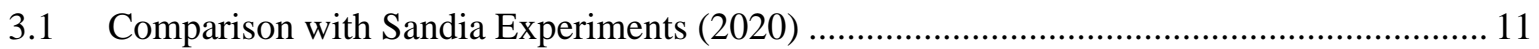

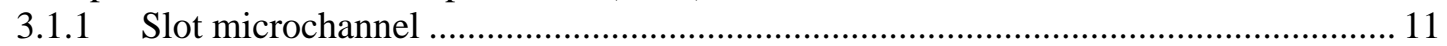

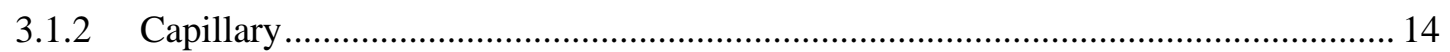

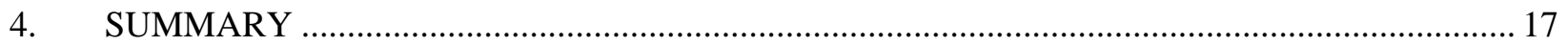

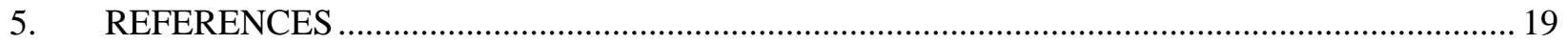


This page is intentionally left blank. 


\section{LIST OF FIGURES}

Figure 1. Block diagram for numerical solution of the aerosol transport equation [Chatzidakis 2018b].

Figure 2. Slot (left) and cylindrical (right) microchannel dimensions (pre-aerosol measurements) [Sandia, 2020].

Figure 3. Flow rate vs. pressure differential (pre-aerosol measurements). 12

Figure 4. Flow rate vs. pressure differential - log scale (pre-aerosol measurements). 12

Figure 5. Friction factor vs. Reynolds number for different pressure differentials (pre-aerosol measurements).

Figure 6. Flow rate vs. pressure difference for rectangular geometry [Gelain and Vendel, 2007]. Friction factor vs. Reynolds number for crack-like geometries; the transition from laminar to turbulent flow occurs at $\mathrm{Re}=5-10$.

Figure 7. Flow rate vs. pressure difference for cylindrical geometry [Sutter et al., 1979]. Friction factor vs. Reynolds number for capillaries; the transition from laminar to turbulent flow occurs at $\mathrm{Re}=400$.

Figure 8. Flow rate vs. pressure difference for capillary (grey: Blasius correlation; orange: empirical correlation from [Sandia 2009]; blue: empirical correlation from [Wißdorf 2016]).

Figure 9. Flow rate vs. pressure difference for capillary - log scale (grey: Blasius correlation; orange: empirical correlation from [Sandia 2009]; blue: empirical correlation from [Wißdorf 2016]).

Figure 10. Friction factor vs. Reynolds number (blue: laminar friction factor; grey: Blasius correlation; orange: friction factor as derived from measurements). 


\section{LIST OF TABLES}

Table 1. Summary of aerosol model characteristics. ........................................................................ 2

Table 2. Summary of aerosol tests in open literature and aerosol model validation status. *..................... 3 


\section{ACRONYMS}

CISCC chloride-induced stress corrosion cracking

CFR US Code of Federal Regulations

DOE US Department of Energy

DPC dual-purpose canister

DSS dry storage system

EPRI Electric Power Research Institute

GDE general dynamic equation

NWTRB US Nuclear Waste Technical Review Board

ORNL Oak Ridge National Laboratory

SCC stress corrosion cracking 
Progress Report on Model Development for the Transport of Aerosol Through Microchannels

This page is intentionally left blank. 


\section{SPENT FUEL AND WASTE DISPOSITION PROGRAM PROGRESS REPORT ON MODEL DEVELOPMENT FOR THE TRANSPORT OF AEROSOL THROUGH MICROCHANNELS}

\section{INTRODUCTION}

Accuracy of consequence assessments could be improved by accounting for the leak path deposition of aerosol in the source term. Recent experimental measurements from Sandia (2018) provided evidence of partial microchannel plugging due to particulate deposition. This filtration effect is relevant to the source term assessments and it is not unreasonable to anticipate that aerosol deposition in realistic geometries with tortuosity and roughness could even lead to plugging of the leak path. Further research into this phenomenon is desirable.

\subsection{Background}

Modeling aerosol transport, retention, and plugging involves the thermal-hydraulic behavior of the canister and of the microchannel/crack, as well as the geometric characteristics of the microchannel/crack and the aerosol features. The minimum set of parameters that needs to be identified includes the following.

- Thermo-hydraulics: Within this group, the most important parameters are the pressure inside the canister, gas composition, pressure drop, and the wall temperature along the crack.

- Crack geometry: The parameters to be considered are mainly the crack path and its hydraulic diameter; information on the crack section shape and curvature is also very important.

- Aerosol features: Aerosol average composition, concentration, and size distribution are the reference parameters, while others, regarding aerosol morphology, can be only taken with large uncertainties.

A compilation of available data in support of model development, including (1) canister characteristics, e.g., pressure, temperature, heat load, environmental conditions, etc., (2) particle size distribution within canister for various scenarios, (3) crack characteristics, e.g., size, opening, roughness, etc., and (4) past models and experiments involving aerosol transport can be found in [Chatzidakis, 2018a].

\subsection{Modeling Capabilities}

A phenomenological model based on the aerosol general dynamic equation (GDE) is currently under development with the goal to accurately simulate aerosol transport and deposition through microchannels. The model can simulate rough or smooth surfaces, irregular geometries, and unsteady flow. Four main deposition mechanisms - gravitational, Brownian diffusion, turbulent diffusion, and eddy impactionhave been included. Laminar, transition, and turbulent gas flow regimes have also been included in the model. The proposed model is being tested and compared with experimental and theoretical work to evaluate its validity and identify its range of applicability.

A wide range of particle size, distribution, pressure differential, flow regimes, and microchannel dimensions can be simulated using the current model. The model can predict pressure change over time due to depressurization (transient state) and particle deposition within a large vessel, such as a canister, before, during, and following depressurization. A summary of the model characteristics is presented in Table 1. A summary of current validation status is shown in Table 2. 
Table 1. Summary of aerosol model characteristics.

\begin{tabular}{|l|l|}
\hline Particle diameter & $0.01 \mu \mathrm{m}-10 \mu \mathrm{m}$ \\
\hline Particle distribution & Monodisperse / Polydisperse \\
\hline Pressure & $4 \mathrm{~Pa}-700 \mathrm{kPa}$ \\
\hline Microchannel dimensions & $5 \mu \mathrm{m}-1 \mathrm{~mm}$ \\
\hline Coagulation & Yes \\
\hline Deposition mechanisms & $\begin{array}{l}\text { Brownian, Gravitational, Turbulent, Inertial, } \\
\text { Thermophoresis }\end{array}$ \\
\hline Plugging & Yes \\
\hline Steady state & Yes \\
\hline Transient state & Yes \\
\hline Flow regimes & Laminar, Transition, Turbulent, Choked \\
\hline Depressurization & Yes \\
\hline Fluid & Air, He \\
\hline
\end{tabular}

\subsection{Purpose}

This report summarizes current progress (as of end of Q3 FY20) on the development of a phenomenological model of aerosol transport, deposition, and plugging through microchannels. The purpose is to introduce a generic, reliable numerical model for the prediction of aerosol transport, deposition, and plugging in leak paths that are similar to stress corrosion cracks (SCCs) while accounting for potential plugging formation.

This report includes (1) an overview of recent additions and improvements to the numerical model to analyze the various deposition processes in leak paths, to provide quantitative estimates of penetration factors, and to gain an understanding of the variables that affect them and (2) a summary of recent benchmarking results of the model's validity with recent experimental measurements from Sandia. 
Table 2. Summary of aerosol tests in open literature and aerosol model validation status.*

\begin{tabular}{|c|c|c|c|c|c|c|c|}
\hline Experiment & Type & Material & $\Delta \mathbf{P}$ & dp & $\mathrm{D}($ or $\mathbf{H} \times \mathbf{W})$ & $\mathbf{L}$ & Validation status \\
\hline $\begin{array}{l}\text { Morton \& Mitchell } \\
(1994)\end{array}$ & Capillary & $\mathrm{n} / \mathrm{a}$ & $20-80 \mathrm{kPa}$ & $1-10 \mu \mathrm{m}$ & $28-35 \mu \mathrm{m}$ & $19-21 \mathrm{~mm}$ & Completed \\
\hline Lewis (1995) & Slot & $\mathrm{n} / \mathrm{a}$ & $10 \mathrm{kPa}$ & $1-6 \mu \mathrm{m}$ & $100 \mu \mathrm{m} \times 40 \mathrm{~mm}$ & $\mathrm{n} / \mathrm{a}$ & Completed \\
\hline Mosley et al. (2001) & Slot & Aluminum & $2-20 \mathrm{~Pa}$ & $0.05-5 \mu \mathrm{m}$ & $508 \mu \mathrm{m} \times 433 \mathrm{~mm}$ & $102 \mathrm{~mm}$ & Completed \\
\hline Liu \& Nazaroff (2003) & Slot & Concrete & 4-10 Pa & $0.02-7 \mu \mathrm{m}$ & $0.25 \mathrm{~mm}, 1 \mathrm{~mm}$ & $4.5 \mathrm{~cm}$ & Completed \\
\hline Gelain \& Vendel (2007) & Crack & Concrete & $0-12 \mathrm{kPa}$ & $\begin{array}{c}0.8 ; 1.1 ; 4.1 \\
\mu \mathrm{m}\end{array}$ & $49.2 \mu \mathrm{m} \times 11.8 \mathrm{~m}$ & $0.1 \mathrm{~m}$ & Completed \\
\hline Tian et al. (2017) & Capillary & Silica & $60-450 \mathrm{kPa}$ & $<0.3 \mu \mathrm{m}$ & $5-20 \mu \mathrm{m}$ & $10-80 \mathrm{~mm}$ & Completed \\
\hline Lai et al. (2012) & Slot & Aluminum & $2-8 \mathrm{~Pa}$ & $20-500 \mathrm{~nm}$ & $50 \mathrm{~mm} \times 250 \mathrm{~mm}$ & $90 \mathrm{~mm}$ & Completed \\
\hline Nelson \& Johnson (1975) & Capillary & $\mathrm{n} / \mathrm{a}$ & $3 \mathrm{kPa}$ & $3-5 \mu \mathrm{m}$ & $520 \mu \mathrm{m}, 1,070 \mu \mathrm{m}$ & $4-8 \mathrm{~cm}$ & In progress \\
\hline Sandia (2018-Present) & Slot & Steel & $700 \mathrm{kPa}$ & $1 \mu \mathrm{m}$ & $28.9 \mu \mathrm{m} \times 8.86 \mathrm{~mm}$ & $12.7 \mathrm{~mm}$ & In progress \\
\hline
\end{tabular}

*dp: particle diameter; D: diameter (for capillary); H×W: height $\times$ width (for slot or crack); L: length 
This page is intentionally left blank. 


\section{OVERVIEW OF AEROSOL TRANSPORT MODEL}

This section presents an overview of the phenomenological aerosol transport and plugging model. The model is described in more detail in [Chatzidakis 2018b and Chatzidakis 2019], and only the main features are summarized in this section. Overall, the model can predict important quantities such as plug mass, gas passed, plugging time, plug profile, and aerosol penetration or retained fraction.

\subsubsection{Aerosol Coagulation and Deposition within Canister}

Coagulation and deposition are inherent properties of aerosols. Whether coagulation of an aerosol in a canister is an important process depends on the aerosol concentration as well as on canister size and shape. Aerosol deposition on canister walls typically occurs from a cloud with homogeneous distribution due to thermal flow convection. Deposition happens through the boundary layer at the walls and is only possible when the particles penetrate into the stagnant boundary layer in contact with the walls.

Gravitational deposition will occur through the boundary layer near upward facing horizontal surfaces whereas deposition due to Brownian diffusion will occur through the boundary layer towards the whole internal surface. Deposition in non-isothermal cases takes place through the boundary layer near the cold walls. Typically, larger particles $(>1 \mu \mathrm{m})$ are removed by gravitation deposition whereas smaller particles $(<0.1 \mu \mathrm{m})$ deposit due to diffusive deposition. Lower initial mass concentration and higher vessel height result in higher aerosol stability and lower deposition rates.

The coagulation and deposition can be described using the principle of mass conservation when applied to aerosol particles inside a canister:

$$
\frac{d C_{1}}{d t}=-K_{1 c} C_{1}^{2}-\frac{Q(t) C_{1}}{V_{1}}-\left(K_{1 g}+K_{1 d}\right) C_{1},
$$

where $K_{l c}$ is the coagulation decay rate, $C_{l}$ is the particle concentration, $t$ is time, $Q$ is the volumetric flow rate, $V_{l}$ is the canister's free volume, $K_{l g}$ is the particle decay rate due to gravitational settling, and $K_{l d}$ is the particle decay rate due to diffusion to the surfaces. The first and second terms on the right side represent the rate at which particles are removed from the canister by coagulation and airflow, respectively. The third term represents the rate at which particles are removed by deposition mechanisms on surfaces other than a microchannel.

A temperature difference of $0.01^{\circ} \mathrm{C}$ in a canister with an effective wall length of one meter is capable of keeping an aerosol consisting of particles smaller than $10 \mu \mathrm{m}$ homogenously distributed inside the canister. When the particle size is so large that the deposition velocity approaches the velocity of the free convection there will arise inhomogeneous aerosol distribution. The particle diameter at which this occurs can be obtained by taking the Stokes' settling velocity equal to the velocity of the free convection given by the Prandtl relation:

$$
\frac{\rho g}{18 \mu} d_{\max }^{2} F\left(d_{\max }\right)=0.5 \sqrt{g a \Delta T l},
$$

where $\mu$ is the viscosity of the gas, $\alpha$ is the coefficient of thermal expansion of the gas, $\Delta T$ is the average temperature difference causing the convection, $\rho$ is the particle density, and $l$ is the wall length. $\mathrm{F}\left(\mathrm{d}_{\max }\right)$ may be taken unity for $\mathrm{d}_{\max }$ larger than 1 and then the following relation holds:

$$
d_{\max }=3\left(\frac{\mu}{\rho}\right)^{1 / 2}\left(\frac{a \Delta T l}{g}\right)^{1 / 4},
$$

For the usual range of canister volumes and $\Delta T=0.01^{\circ} \mathrm{C}, \mathrm{d}_{\max }$ ranges from $18-24 \mu \mathrm{m}$ (aerodynamic diameter). Clearly, respirable aerosol particles of a few $\mu \mathrm{m}$ or less would remain homogeneously distributed within a canister. Another way to interpret this result is to compare the convective flow 
velocity which is in the order of $10-20 \mathrm{~cm} / \mathrm{s}$ or higher to the particle's settling velocity which is several orders of magnitude lower $\sim 10^{-3} \mathrm{~cm} / \mathrm{s}$.

Within a canister, a homogeneously distributed monodisperse aerosol will decay exponentially due to gravitational settling with a decay constant:

$$
\beta_{s}=v_{s} \frac{S_{f}}{V}
$$

where $v_{s}$ is the Stokes settling velocity, $S_{f}$ the projected aera of the canister, and $V$ is the canister volume. For a typical vertical canister with $v_{s}=3 \times 10^{-5} \mathrm{~m} / \mathrm{s}, S_{f}=1 \mathrm{~m}^{2}$ and $V=6 \mathrm{~m}^{3}$, the decay constant for particles of $1 \mu \mathrm{m}$ aerodynamic diameter is $0.02 \mathrm{hr}^{-1}$ which translates to a half-life of $34.6 \mathrm{hrs}$. For $0.1 \mu \mathrm{m}$ aerodynamic diameter the decay constant is $0.002 \mathrm{hr}^{-1}$ with a half-life of $346 \mathrm{hrs}$. Similarly, for $10 \mu \mathrm{m}$ aerodynamic diameter, the decay constant is $0.2 \mathrm{hr}^{-1}$ with a half-life of $3.46 \mathrm{hrs}$. Coagulation and diffusive deposition are expected to decrease these times even further.

\subsubsection{Aerosol Transport through Microchannel}

For the case of aerosol penetration through a microchannel assuming only external processes the general dynamic equation (GDE) is reduced to a transport equation, which can be written as follows in onedimensional form [Mitrakos et al. 2008; Chatzidakis and Scaglione 2019]:

$$
\frac{\mathrm{dC}(\mathrm{x}, \mathrm{t})}{\mathrm{dt}}+\frac{1}{A(\mathrm{x}, \mathrm{t})} \frac{d}{d x}[A(\mathrm{x}, \mathrm{t}) \cdot u(\mathrm{x}, \mathrm{t}) \cdot C(\mathrm{x}, \mathrm{t})]=-\mathrm{V}_{d}(\mathrm{x}, \mathrm{t}) \frac{\chi(\mathrm{x}, \mathrm{t})}{A(\mathrm{x}, \mathrm{t})} C(\mathrm{x}, \mathrm{t}),
$$

where $C$ is the aerosol mass concentration, $V_{d}$ is the deposition velocity, $A$ is the cross-sectional area, $\chi$ is the wetted perimeter of the cross section, and $u$ is the gas velocity. All previous parameters are functions of the axial coordinate $x$ and time $t$. The deposition velocity is calculated as the sum of the deposition velocities corresponding to each individual deposition mechanism.

Four deposition mechanics are considered herein: gravitational settling, Brownian diffusion, inertial impaction, and eddy impaction for the case of turbulent flow conditions. These deposition mechanisms play a crucial role in aerosol retention within a microchannel and are described in more detail in a previous report [Chatzidakis 2018b]. Other deposition mechanisms, such as electrophoresis and diffusiophoresis, are neglected, as preliminary calculations indicate that these mechanisms are relatively unimportant in the removal of particles.

Generally, diffusion governs the deposition of particles with $\mathrm{d}_{\mathrm{p}}<0.1 \mu \mathrm{m}$. Inertial deposition in the high flow rate regime and gravitational settling in the low flow rate regime govern the deposition for particles having diameter $d_{p}>1 \mu m$.

\subsubsection{Flow Rate}

Flow of gas at the microscale has fundamental differences with respect to flow at the conventional scales. The primary difference is that slipping of gas may occur at solid-gas interface, as opposed to no-slip boundary conditions at the conventional scales. The flow is also usually accompanied by a substantial change in the density of the gas. These effects are quantified in terms of non-dimensional parameters Knudsen number (Kn) and Mach number (Ma). For $\mathrm{Kn}<10^{-3}$, the flow is a continuum flow and it is modeled by the Navier-Stokes equations with classical no-slip boundary conditions. For $10^{-3}<\mathrm{Kn}<10^{-1}$, the flow is a slip flow and the Navier-Stokes equations remain applicable, provided a velocity slip and a temperature jump are taken into account at the walls. For $10^{-1}<\mathrm{Kn}<10$, the regime is a transition regime and the continuum approach of the Navier-Stokes equations is no longer valid. For $\mathrm{Kn}>10$, the regime is a free molecular regime and the occurrence of intermolecular collisions is negligible compared with the one of collisions between the gas molecules and the walls.

For air in standard conditions (i.e., for $\mathrm{T}=273.15 \mathrm{~K}$ and $\mathrm{P}=1.013 \cdot 10^{5} \mathrm{~Pa}$ ) the mean free path is $\lambda=59 \mathrm{~nm}$. A slot (rectangular) microchannel with characteristic height $\mathrm{L}=28.9 \mu \mathrm{m}$ would result in $\mathrm{Kn}=2 \cdot 10^{-3}$ which 
is in slip flow regime. For a capillary with characteristic dimension $\mathrm{d}=152.4 \mu \mathrm{m}$ would result in $\mathrm{Kn}=0.38 \cdot 10^{-3}$.

The aerosol transport equation given above can be applied to any cross-sectional shape for which the hydraulic diameter and mass flow rate are known. The mass flow rate $Q_{\mathrm{m}}$ for continuum flow can be written as a function of the pressure drop along the flow direction (Williams 1994):

$$
p_{u}^{2}-\mathrm{p}_{d}^{2}=\mathrm{R}_{g} \mathrm{TQ}_{m}^{2} \int_{0}^{L} C_{f}(\mathrm{Re}) \frac{\chi(x)}{A^{3}(x)} \mathrm{dx},
$$

where $x$ is the axial distance from the inlet of the crack (or capillary), $p_{u}$ and $p_{d}$ are the pressures at the upstream and at the downstream of the crack, respectively, $L$ is the length of the duct, $\chi$ is the perimeter of the duct, and $A$ is the cross-sectional area. This equation can be solved numerically to determine the mass flow rate $Q_{\mathrm{m}}$. When this is known, the velocity and volume flow rate can be calculated using mass continuity.

\subsubsection{Plugging}

A leak path through which aerosol passes and is deposited may become partially or completely plugged. The particulate matter will deposit on the surface, changing the internal geometry of the flow area. Eventually the plug mass will increase and will lead to a complete obstruction of the pathway.

The mass of the deposit up to any position $S$ can be obtained in terms of the deposition velocity and the particle concentration as follows:

$$
M_{\text {dep }}=\int_{0}^{S} \int_{0}^{t} 2 \pi R C V_{d} d x d t .
$$

Assuming that the deposit material is homogeneous with a density equal to the density of the particles, then the volume of the deposit can be directly derived from its mass:

$$
V_{d e p}=\frac{M_{d e p}}{\rho_{p}} .
$$

In Eq. (4) above, density $\rho_{p}$ is assumed to be the bulk material density. This approximation is more accurate for large particles that are deposited mainly by gravity or eddy impaction. The deposition of particles is assumed to occur uniformly on the path's circumference. This assumption is valid for mechanisms such as Brownian or turbulent diffusion or for eddy impaction, but it is approximate for directional mechanisms such as gravitational settling. Under this assumption, the change in radius due to plugging is related to the deposit volume, as follows:

$$
d R=\frac{1}{2 \pi R} \frac{d V_{d e p}}{d x} .
$$

The aerosol transport equation, Eq. (4), is solved using an implicit finite difference scheme. The upwind scheme is used for the discretization of the convection term, which is the second term on the left-hand side of Eq. (4). The duct radius is then updated according to Eq. (7) through calculating the amount of the deposited mass, as shown in Eqs. (8) and (9). All the numerical integrations required in this calculation are performed using the trapezoidal rule. The new cross section is then used for the aerosol calculations in the next step (Figure 1).

\subsubsection{Depressurization and Transient State}

The model described above assumes deposition only within a microchannel under constant (steady state) conditions, and it does not take any depressurization events into account that may influence deposition. To address these shortcomings, a depressurization equation was added to the model to account for 
pressure change over time (transient state). Furthermore, the model was extended to account for coagulation and deposition within a vessel such as a canister, with dimensions much larger than that of a microchannel. In this case, aerosol reduction due to coagulation and deposition mechanisms within a large vessel and within a microchannel can be predicted before, during, and after depressurization.

Combining mass and energy conservation equations for vessel depressurization, one can arrive at the following formula:

$$
\frac{d P_{\text {vessel }}}{d t}=-\frac{Q_{m} P_{\text {vessel }} \gamma_{g}}{M_{\text {vessel }}}
$$

where $\gamma_{g}$ is the ratio of specific heat capacity at constant pressure and volume. Applying the forward Euler method (explicit) to iterate pressure over time, it is possible to follow the pressure changes in the system and extract the time when pressures will equalize. 


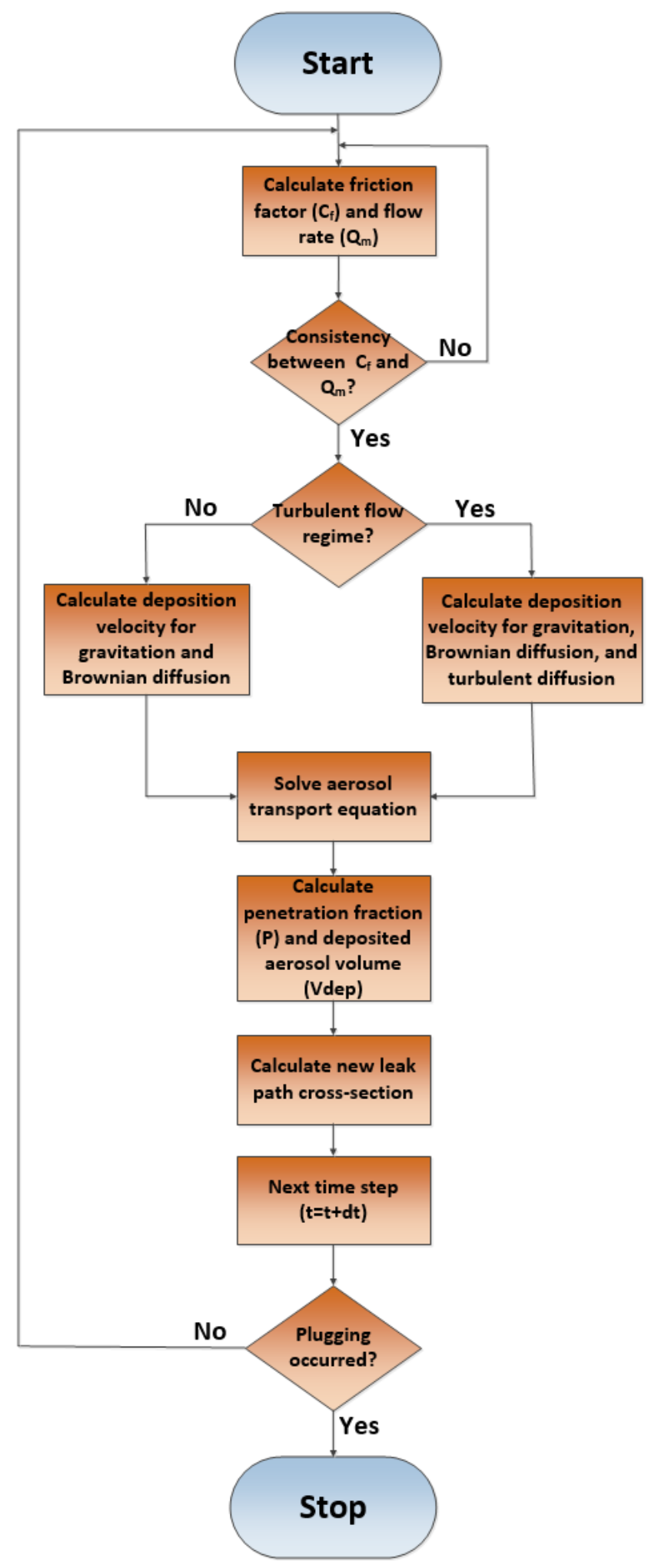

Figure 1. Block diagram for numerical solution of the aerosol transport equation [Chatzidakis 2018b]. 
This page is intentionally left blank. 


\section{BENCHMARKING RESULTS}

The model described in Section 2 was benchmarked against recent flow-rate measurements in microchannels including slot and capillaries performed by Sandia. Previous validation results against experimental measurements of particle penetration and plugging in leak paths under a variety of conditions in tubes, slots, or real cracks can be found in [Chatzidakis 2019].

\subsection{Comparison with Sandia Experiments (2020)}

Sandia performed flow-rate measurements on slot (rectangular) and cylindrical microchannel geometries. The dimensions are shown below.
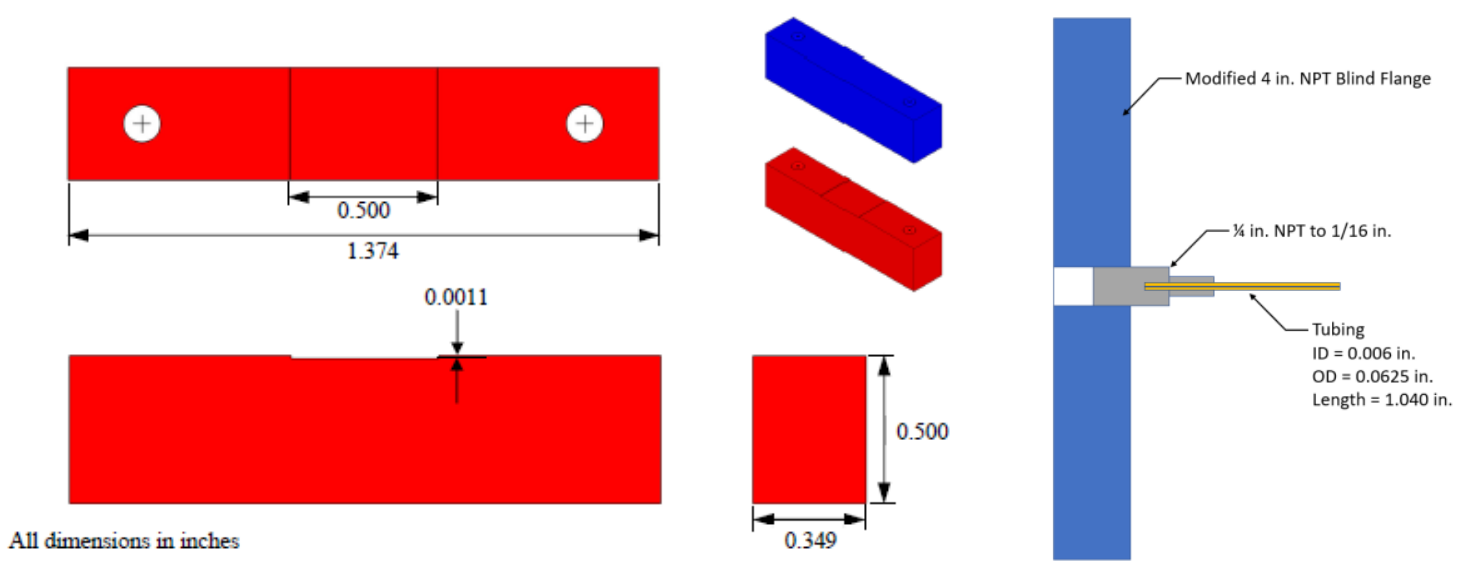

Figure 2. Slot (left) and cylindrical (right) microchannel dimensions (pre-aerosol measurements) [Sandia, 2020].

\subsubsection{Slot microchannel}

The results of the present model vs. Sandia's experimental flow-rate measurements are shown in Figures 3-5. It is noted that the measurements were taken before aerosol was released into the tank, so there was no aerosol influence (pre-aerosol measurements). The following observations were made.

- A flow rate based on conventional laminar friction factor significantly overestimates the flow rate.

- Agreement is observed only in very low pressure differentials, less than $100 \mathrm{kPa}$. Above $100 \mathrm{kPa}$, the results diverge significantly independent of laminar or turbulent regime.

- Flow is subsonic for pressure differentials less than $370 \mathrm{kPa}$. However, models of adiabatic choked flow did not capture the measurements.

- Trials with different friction factor correlations were performed, but none successfully reproduced the experimental measurements.

- Plotting friction factor vs. Reynolds number (Figure 5) indicates that measured friction factor (as derived from flow rate) diverges from laminar friction factor at $\mathrm{Re}>100$. A new friction factor correlation is needed to capture this trend and correctly match the measured flow rate. 


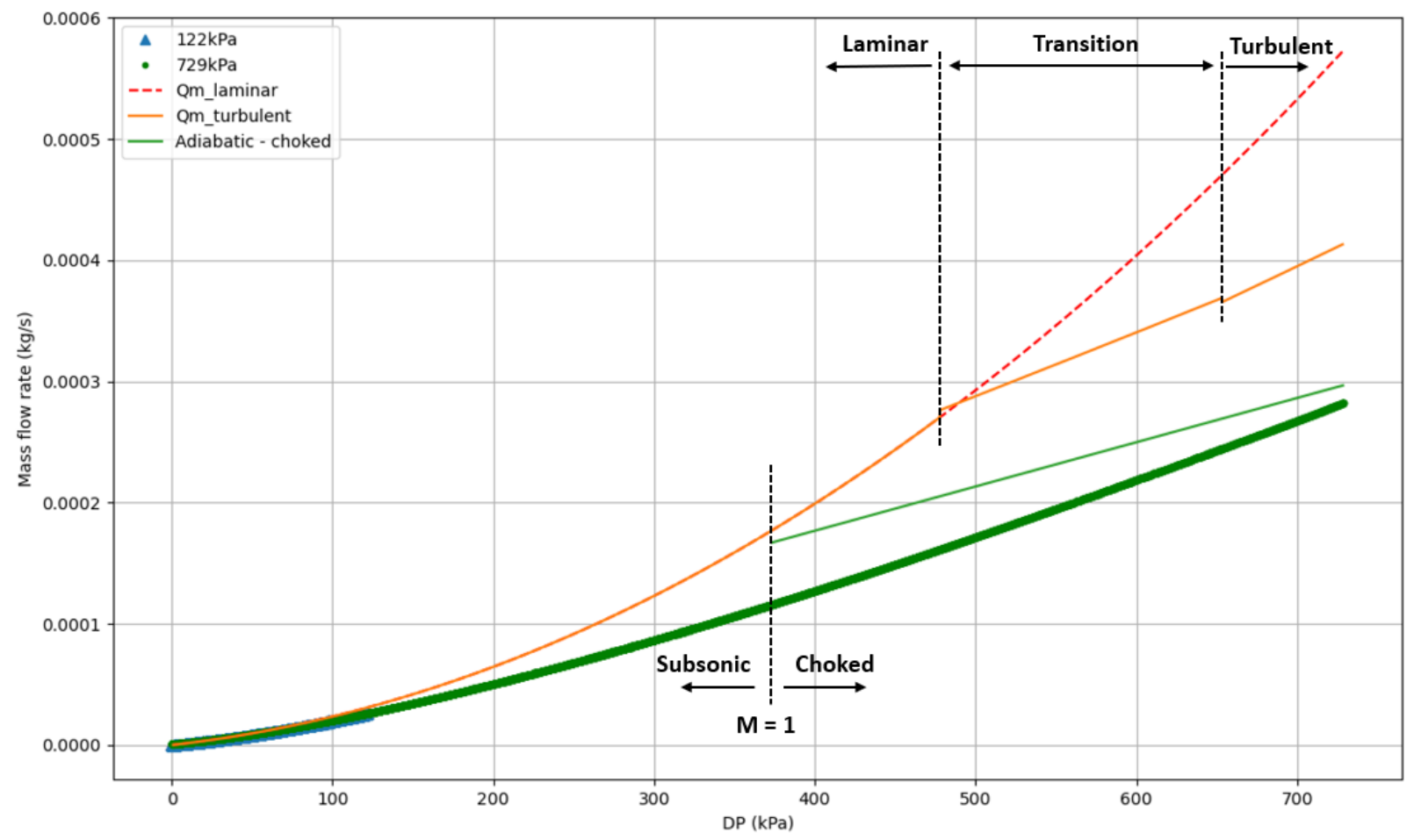

Figure 3. Flow rate vs. pressure differential (pre-aerosol measurements).

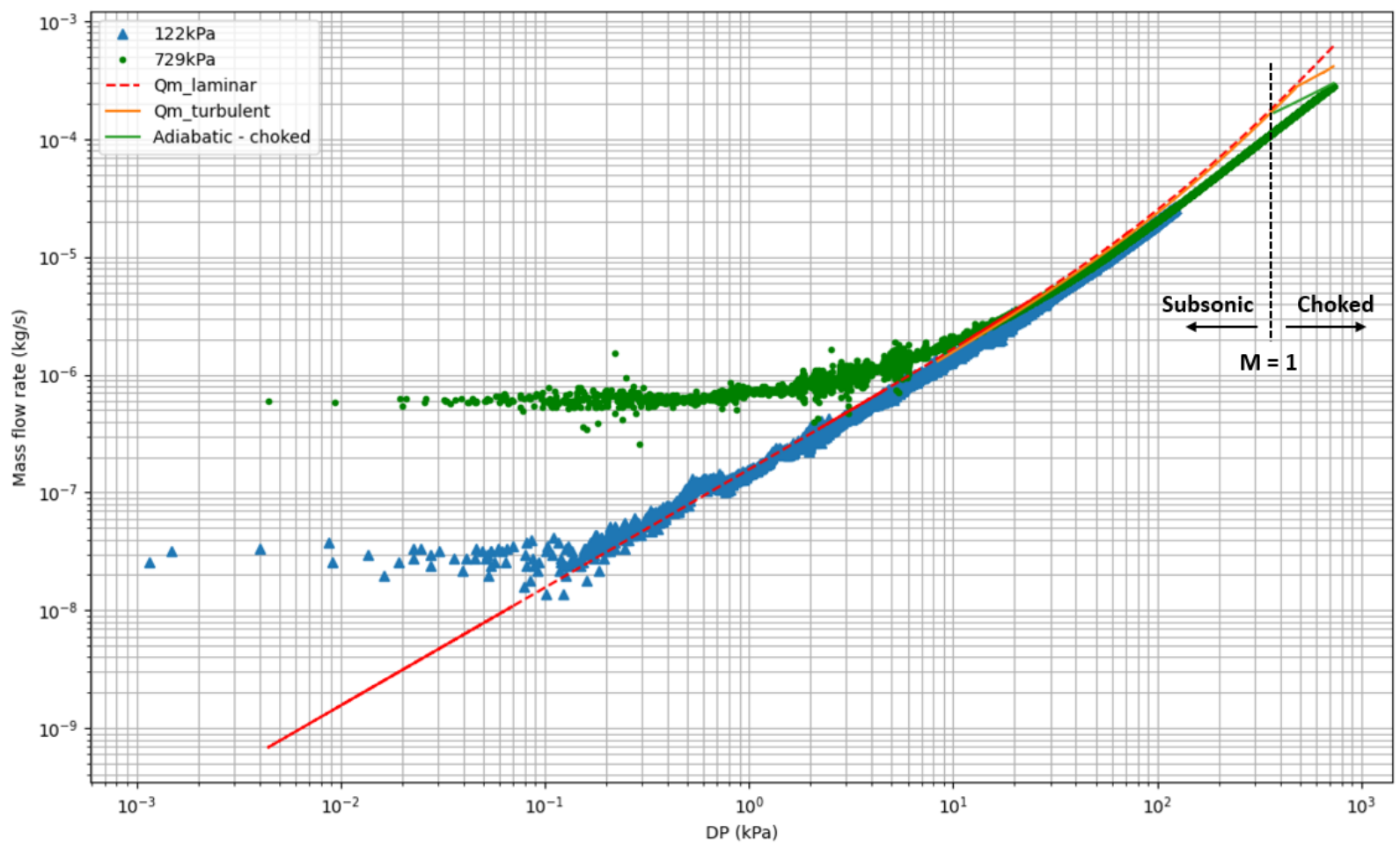

Figure 4. Flow rate vs. pressure differential - log scale (pre-aerosol measurements). 

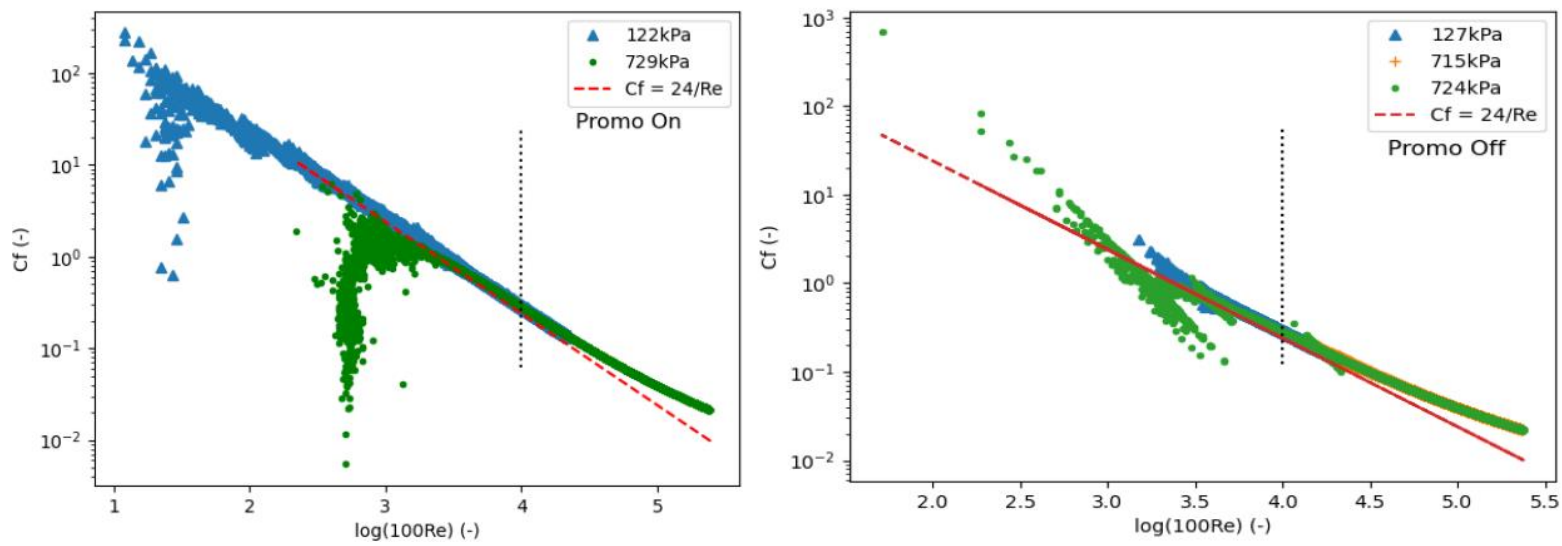

Figure 5. Friction factor vs. Reynolds number for different pressure differentials (pre-aerosol measurements).

It is noted that similar divergent behavior of flow rate from laminar regime in microchannels was observed in other experiments available in literature, for example, one in rectangular (crack-like) geometries [Gelain and Vendel 2007] and one in capillaries of various diameters [Sutter et al. 1979]. The results of the present model vs. experimental measurements are shown in Figures 6 and 7.

For rectangular geometries, transition to turbulent flow regime starts at $\operatorname{Re}=5-10$. For cylindrical geometries, transition to turbulent flow regime starts at $\operatorname{Re}=400$. This is contrary to the widely used $\operatorname{Re}=$ $2300-4000$.
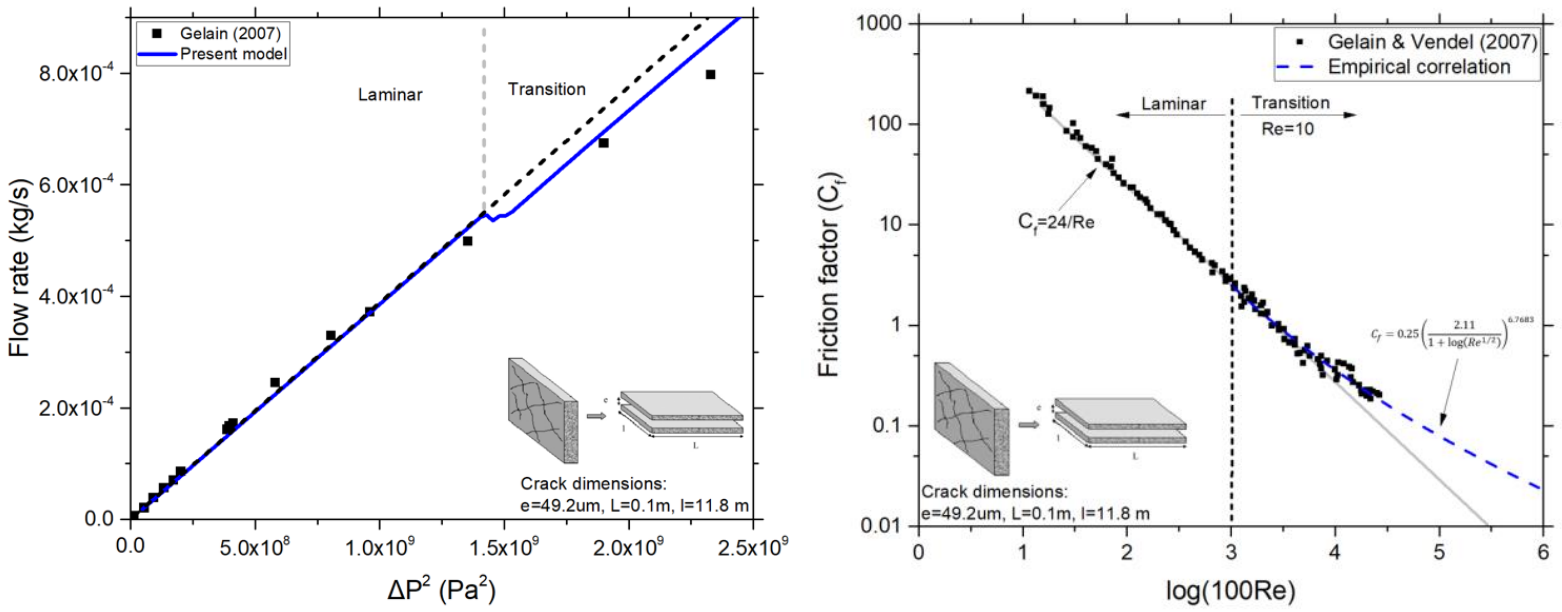

Figure 6. Flow rate vs. pressure difference for rectangular geometry [Gelain and Vendel, 2007]. Friction factor vs. Reynolds number for crack-like geometries; the transition from laminar to turbulent flow occurs at $\operatorname{Re}=\mathbf{5}-\mathbf{1 0}$. 

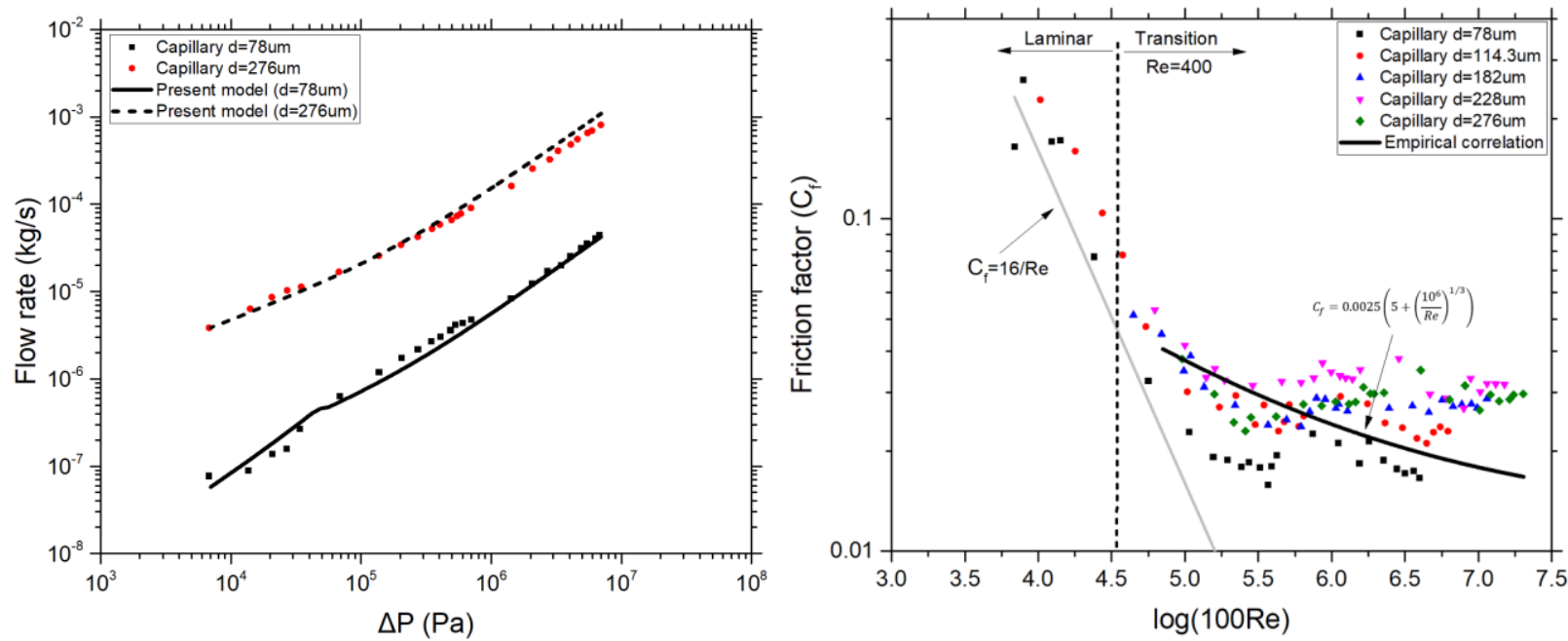

Figure 7. Flow rate vs. pressure difference for cylindrical geometry [Sutter et al., 1979]. Friction factor vs. Reynolds number for capillaries; the transition from laminar to turbulent flow occurs at $\operatorname{Re}=400$.

\subsubsection{Capillary}

Similar conclusions were reached when comparing various friction factors and correlations with capillary flow rate measurements. Figures 8-10 show how different correlations compare against measurements. In this case, the flow regime is turbulent for $\Delta \mathrm{P}>50 \mathrm{kPa}$. However, the Blasius friction factor correlation underestimates the flow rate by a factor of 2 . Conventional friction factors fail to capture the underlying phenomena in microchannels. A proposed empirical correlation from [Sandia, 2009] underestimates the flow rate by a factor of 5. However, an empirical correlation found in [Wißdorf 2016] appears to be in good agreement with measurements.

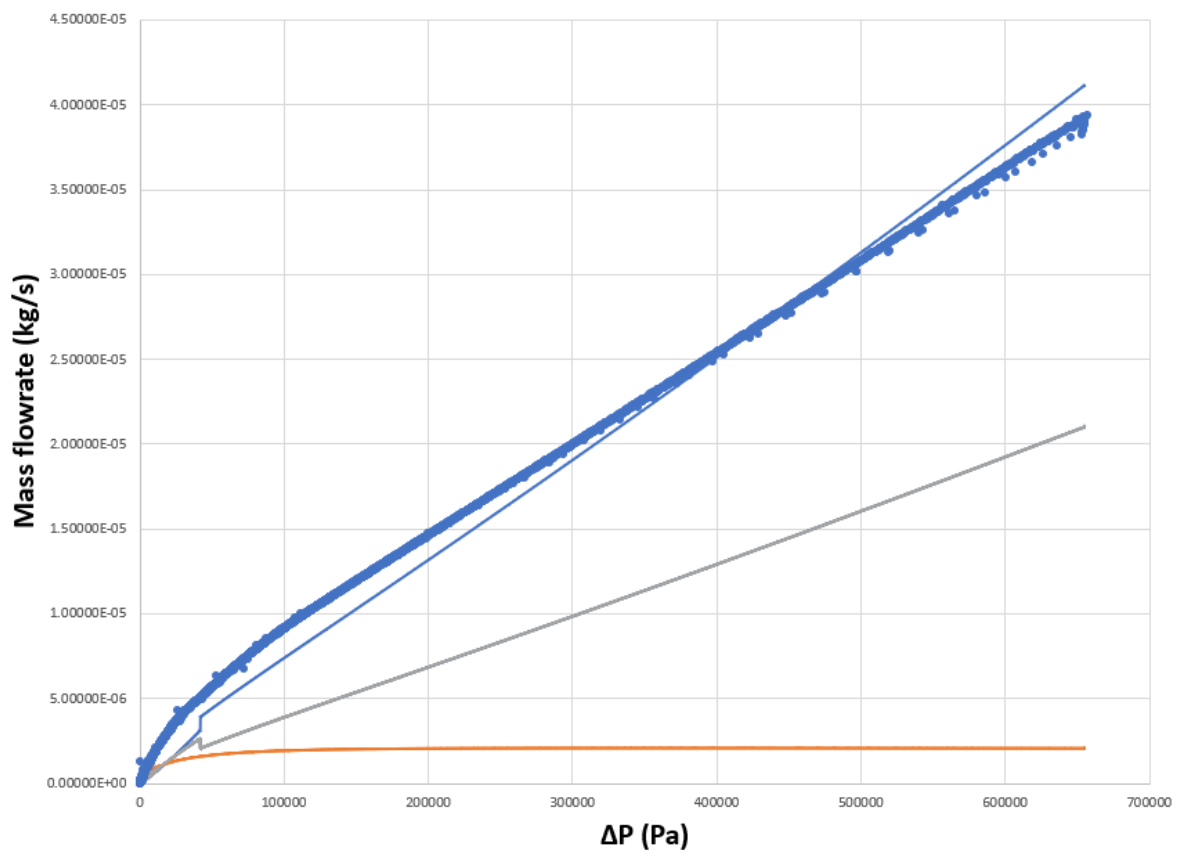

Figure 8. Flow rate vs. pressure difference for capillary (grey: Blasius correlation; orange: empirical correlation from [Sandia 2009]; blue: empirical correlation from [Wißdorf 2016]). 


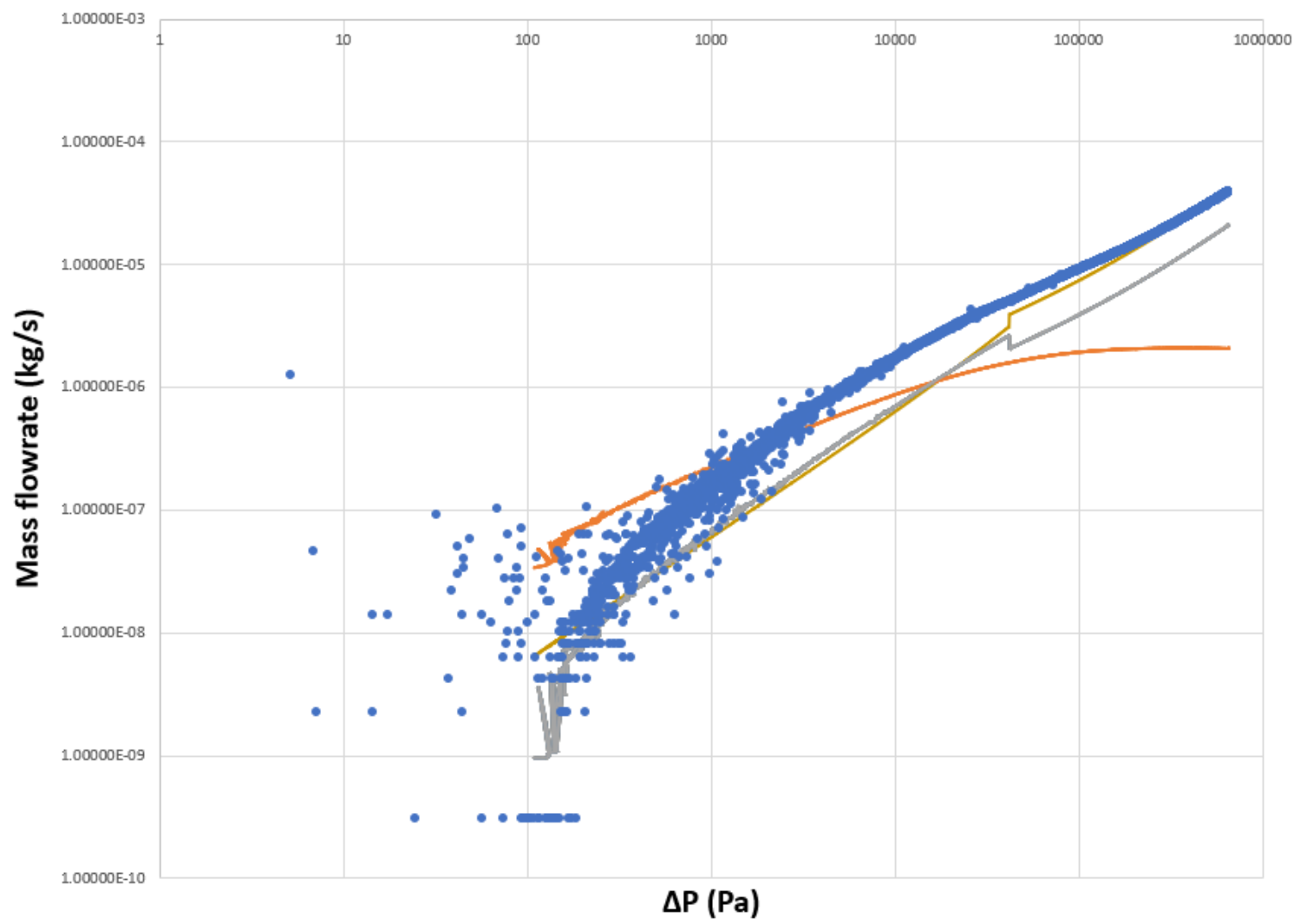

Figure 9. Flow rate vs. pressure difference for capillary - log scale (grey: Blasius correlation; orange: empirical correlation from [Sandia 2009]; blue: empirical correlation from [Wißdorf 2016]).

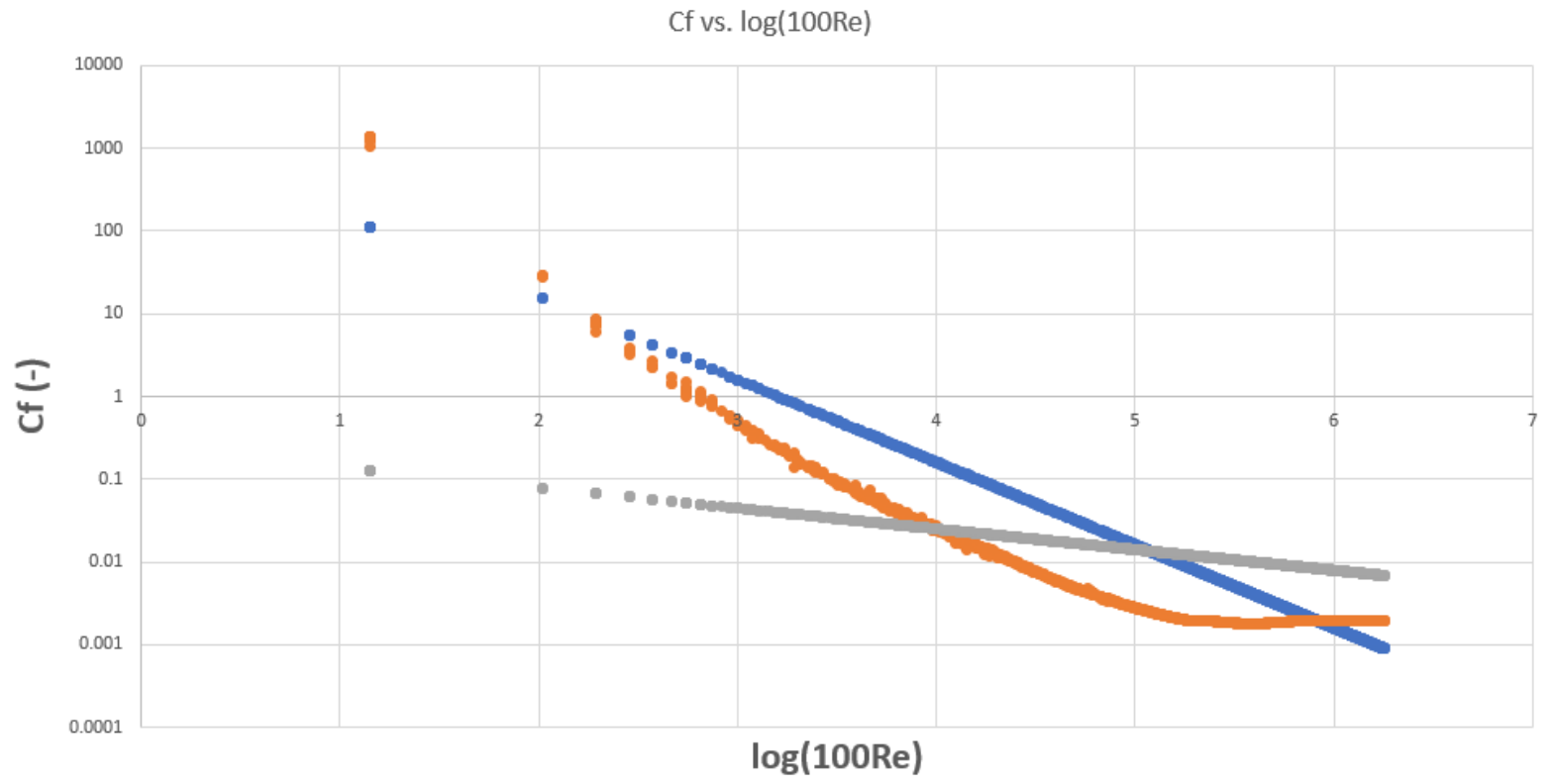

Figure 10. Friction factor vs. Reynolds number (blue: laminar friction factor; grey: Blasius correlation; orange: friction factor as derived from measurements). 
This page is intentionally left blank. 


\section{SUMMARY}

A phenomenological model is currently under development that enables the calculation of aerosol transport and retention in leak paths and that also accounts for plugging formation. The model assumes a one-dimensional flow through a hydraulically equivalent leak path. The description is dynamical, with changing duct geometry due to plugging, and it is also mechanistic. An extensive validation exercise (particle diameters: $0.01-10 \mu \mathrm{m}$ and pressure difference up to $700 \mathrm{kPa}$ ) is in progress based on comparisons with experimental measurements and empirical correlations. The model predictions are in approximate agreement with experimental data and are reasonably representative.

Further progress will require (1) improvements to further refine the model and (2) additional experimental studies for model validation. It is recommended that future experiments address:

- Flow rates for various pressures to provide insight on flow regimes and develop friction factor correlations in a microchannel.

- Measurements of aerosol concentration in a canister, including polydisperse aerosol, to better understand aerosol reduction processes such a coagulation and deposition and for model validation.

- Tests that result in complete plugging of a microchannel to better understand aerosol plugging conditions and for model validation.

Advances in this area hold the promise of improving the accuracy of consequence assessments and reducing the uncertainty of radiological consequence predictive analyses by taking the filtering effect of leak path aerosol deposition and plugging into account in the source term. 
This page is intentionally left blank. 


\section{REFERENCES}

Chatzidakis, S. 2018a. Literature Review and Data for Aerosol Model Development. Prepared for DOE, Spent Fuel and Waste Science and Technology Program (ORNL). Report no. ORNL/SPR-2018/1217, Revision 0.

Chatzidakis, S. 2018b. SCC Aerosol Transport Model Summary Report. Prepared for DOE, Spent Fuel and Waste Science and Technology Program (ORNL). Report no. ORNL/SPR-2018/1072, Revision 0.

Chatzidakis, S. 2019. Summary of Aerosol Transport Model Validation. Prepared for DOE, Spent Fuel and Waste Science and Technology Program (ORNL). Report no. ORNL/SPR-2018/1197, Revision 0.

Chatzidakis, S. and Scaglione, J. 2019. A Mechanistic Description of Aerosol Transport and Deposition in Stress Corrosion Cracks, Proceedings of Global/TopFuel Conference 2019, pp. 1033-1039, September 22-27, Seattle, WA.

Gelain, T. and Vendel, J. 2007. "Research works on contamination transfers through cracked concrete walls." Nucl. Eng. Des. 238, 1159-1165.

Lai, A.C.K. et al. (2012). Penetration of fine particles through rough cracks. Atmospheric Environment 60, 436-443.

Lewis, S. (1995). Solid particle penetration into enclosures. Journal of Hazardous Materials 43, 195-216.

Liu, D. and Nazaroff, W. W. 2003. "Particle Penetration through Building Cracks." Aerosol Sci. Technol. $37,565-573$.

Mitrakos, D., et al. 2008. "A simple mechanistic model for particle penetration and plugging in tubes and cracks.” Nucl. Eng. Des. 238, 3370-3378.

Morton, D.A.V. and Mitchell, J.P. 1994. Aerosol penetration through capillaries and leaks: experimental studies on the influence of pressure. J. Aerosol Sci. 26, 353-367.

Mosley, R.B. et al. 2001. "Penetration of ambient fine particles into the indoor environment." Aerosol Sci. Technol. 34, 127-136.

Nelson, C. T., and R. P. Johnson. 1975. Aerosol Leakage Tests, Report ERDA 56.

Sandia 2009. Aerosol Penetration of Leak Pathways - An Examination of the Available Data and Models. Prepared by Dana A. Powers. Report No. SAND2009-1701.

Sandia 2018. Measurement of Particulate Retention in Microchannel Flows. Prepared for DOE Spent Fuel and Waste Science and Technology Program. Durbin, S. (Sandia). Report No. SAND2018-10522 R, Revision 0.

Sutter et al. 1979. Depleted Uranium Dioxide Powder Flow Through Very Small Openings. NUREG/CR1099, PNL-3177, Pacific Northwest Laboratory, Richland, WA.

Tian, M. et al., 2017. "Experimental study on the penetration efficiency of fine aerosols in thin capillaries." Journal of Aerosol Science 111, 26-35.

Wißdorf, W. et al. 2016. "Gas Flow Dynamics in Inlet Capillaries: Evidence for non Laminar Conditions.” J. Am. Soc. Mass Spectrom. 27,1550-1563.

Williams, M. M. R. 1994. "Particle deposition and plugging in tubes and cracks (with special reference to fission product retention)." Progress in Nuclear Energy 28, 1-60. 
This page is intentionally left blank. 